\title{
Pesquisa 4.0: novas dinâmicas de pesquisa e descoberta de informação científica e cooperação entre investigadores
}

Filipe Manuel Santos Bento

Especialista de Informática, Universidade de Aveiro, Portugal. Doutorando ICPD - Informação e Comunicação em Plataformas Digitais (Universidade de Aveiro / Universidade do Porto, Portugal).Bolsa de Doutoramento FCT - Fundação para a Ciência e a Tecnologia.Presidente da Direção da USE.pt (Utilizadores de Sistemas EXLibris de Portugal)

Lídia de Jesus Oliveira

Doutoramento em Ciências e Tecnologias da Comunicação.Professora no Departamento de Comunicação e Arte, Universidade de Aveiro. Investigadora e Coordenadora Científica da Unidade de Investigação CETAC.MEDIA

http://dx.doi.org/10.1590/1981-5344/1831

A comunidade científica passa por uma das fases mais dinâmicas e exigentes da sua existência. Nunca, na sua história, a comunidade foi tão extensa, nunca se publicou tanto como atualmente, nunca o ciclo de vida do conhecimento foi tão curto. Novos dados, novas interpretações, novas teorias e novos membros surgem todos os dias: o número de publicações é imenso e nem sempre é evidente operacionalizar uma estratégia de pesquisa que se revele eficaz e eficiente, para obter informação relevante e significativa. É, neste contexto, que se tem vindo a desenvolver um Serviço que visa agregar um conjunto significativo de recursos, mas, acima de tudo, promover a lógica de cooperação dos utilizadores desses recursos, incentivando-os a acrescentar valor. Deste modo, propõem-se a designação de "Pesquisa 4.0" para este novo paradigma de pesquisa e descoberta, resultante de uma dinâmica social de quatro elementos o investigador, os documentos, os utilizadores (seus pares) e o mapeamento semântico dos metadados; em plena interação potenciada pelo sistema, estes quatro elementos geram uma rede social dinâmica, autossustentável e com garantia de preservação futura; 
uma rede social não só de atores humanos como de recursos, mas, acima de tudo, de um capital social e cultural superior

Palavras-chave: Pesquisa; Serviços de descoberta; Informação científica; Redes sociais; Capital social.

\section{Search 4.0: scientific information search and discovery new dinamics and ways of colaboration amongst researhers}

The scientific community is undergoing one of the most dynamic and demanding times of its existence. Never in its history, the community was so extensive, never published as much as today, never the knowledge life cycle was so short. New data, new interpretations, new theories and new members emerge every day: the number of publications is immense and it is not always clear how to construct a search strategy that proves to be effective and efficient. It is in this context that a new service is being developed aiming to aggregate significant sets of resources and services that until now were dispersed, powering them with innovative features, but above all, promoting a logic of cooperation amongst users of such resources, stimulating a dynamic of "use and add value". Thus, it advanced the term "Search 4.0" for this new paradigm of search, discovery, access, recommendation and sharing of resources, resulting from a natural social dynamic amongst the four key elements user, resources, semantic mapping of metadata and user's communities. In full interaction enhanced by the system, these four elements shall generate a dynamic self-sustainable social network, not only of human actors but also resources themselves taking the role of actors.

Keywords: Research; Discovery services; Scientific information; Social networks; Social Capital

Recebido em 14.06.2013 Aceito em 17.10.2013 


\section{Introdução}

Para além da comunidade nunca ter sito tão extensa como atualmente, de nunca se ter publicado tanto como agora, em especial com os modelos de publicação associados ao Open Access, seja este modelo na sua vertente Via Verde ou Via Dourada, e de nunca o ciclo de vida do conhecimento ser tão curto como o é atualmente, há a acrescentar a informação produzida pelos utilizadores (a chamada User Generated Content (UGC)) associada a esses registos. No atual paradigma, a extensa oferta de serviços de partilha e recomendação, baseados em componentes Web 2.0, é propenso a que a informação fique dispersa por esses vários serviços externos (como é o atualmente, praticamente na integra), ou seja, informação não passível na sua grande maioria de ser integrada ou agregada (e, desse modo, ficando praticamente invisível para os restantes membros da comunidade) ou mesmo sem garantia de preservação futura. Urge, assim, desenhar e colocar em prática uma estratégica, suportada tecnologicamente pelos mesmos componentes que se encontram nesses serviços externos, mas disponibilizados de um modo integrado, localmente, pelas Bibliotecas e Centros de Documentação. Não se deve, contudo, descorar a possibilidade da partilha nesses serviços externos e de os mesmos remeterem para este novo Serviço (local, via link do registo partilhado), mas com todos os comentários e revisões a serem refletidas ou terem uma cópia no sistema de pesquisa e descoberta de informação local. Com esta estratégia, deseja-se dar um duplo contributo à comunidade científica: por um lado, sistematizar e preservar a produção académica e cultural dos membros de uma determinada comunidade (dentro da Universidade ou qualquer outra instituição de Ensino Superior), e, por outro, tornar essa memória acessível para que ela contribua para enriquecer o trabalho desenvolvido, gerando um efeito de conservação e disseminação que contribua para a inteligência coletiva e cognição social desta comunidade e, também, para a comunidade externa.

Este novo modelo de pesquisa, descoberta e partilha de informação deve igualmente passar pela integração do Catálogo e seus acervos bibliográficos, assim como agregar conteúdo de fontes externas e contribuições dos seus utilizadores. Neste modelo, o utilizador e toda a sua envolvente (atividades e informação associada ao seu perfil ou comunidades a que pertença) assumem uma dimensão fundamental na geração de informação adicional, contextualizada às necessidades específicas dos seus utilizadores, promovendo redes sociais entre os mesmos. A análise empírica e o protótipo desenvolvido toma como ponto central o acervo bibliográfico presente nas bibliotecas da Universidade de Aveiro/Portugal e o "ecossistema" de utilizadores e dinâmicas de utilização do acervo, complementando, este, na medida em que tal seja viável, com informação proveniente de outras fontes, quer em nível de resultados finais, quer em nível do auxílio na pesquisa (guidance).

E é esta a visão para um novo Catálogo Bibliográfico, Catálogo 2.0, integrador ao nível dos conteúdos, explorador das ações dos seus utilizadores e agregador das suas contribuições. Este novo conceito de 
Catálogo redefine $\mathrm{o}$ tradicional Catálogo Bibliográfico das obras e conteúdos acessíveis na Biblioteca ou adquiridos para consulta no Campus, estendendo a sua abrangência a todos os recursos que os utilizadores têm a sua disposição, sejam eles locais ou acessíveis remotamente, com manifestações impressas ou em formato digital, adquiridos ou em livre acesso. Por ser "2.0" por natureza, traz para o paradigma dos recursos de informação o que sempre se verificou no resto da academia: em uma fase inicial, os alunos beneficiam de todo o saber acumulado da instituição e, em uma fase mais avançada, contribuem para esse saber, com os seus projetos e investigação de final de curso, dissertações de mestrado e teses de doutorado. Assim, os utilizadores no paradigma do Catálogo 2.0 beneficiam de todo o valor base do recurso em si, mas, também, de toda a informação adicionada por utilizadores anteriores, quer de um modo ativo (adicionando tags, comentários, informação de recursos relacionados, etc.), quer de um modo passivo (pelo empréstimo ou consulta do recurso). E como um mecanismo vivo, os recursos aí referenciados ganham valor pela utilização dada por estes novos atores e pelo valor que acrescentam de um modo ativo aos mesmos. O Catálogo 2.0 rompe com o conceito de Catálogo Bibliográfico clássico, uma mera base de dados do conjunto de recursos, maioritariamente monografias em estantes, com utilização em tudo semelhante à feita nas obras nessas estantes, por não se adicionar valor às mesmas. Em vez disso, o Catálogo 2.0 incentiva a que os utilizadores "sublinhem" passagens do livro, tirem notas, só que em vez de o fazerem diretamente no livro, o façam em uma plataforma digital (Catálogo), em campos próprios associados ao registo da obra.

A presente visão do Catálogo 2.0 leva este conceito ainda mais longe, ao atribuir aos recursos, objetos de informação, também o papel de atores no sistema, tendo estes igualmente uma vida social, de "nascença" (por serem do mesmo autor ["irmãos"], assunto ["primos"]) ou Ihes dada pela utilização e recomendação dos seus utilizadores (por serem de algum modo do mesmo grupo ["amigos"]). Neste modelo de sistema de descoberta, os recursos tornam-se "amigos" dos atores humanos, por terem sido "apresentados" (recomendados) por outros utilizadores. Ao estabelecerem esta ligação, quer os recursos, quer os utilizadores, alargam a sua rede social em novas ramificações de recursos, utilizadores e comunidades.

\section{Pesquisa de Informação: Web 2.0 e Biblioteca 2.0}

Do ponto de vista dos utilizadores, de certa forma, podemos estabelecer uma comparação entre a Web e Biblioteca 1.0 e Web e Biblioteca 2.0. Assim como a Web 1.0 servia "apenas" como fonte, um sítio para "ir e buscar", como Peltier-Davis (2009) indica, sem possibilidade de adicionar ou alterar o conteúdo, a Biblioteca 1.0 caracteriza-se por ser um espaço físico tradicional próprio das Bibliotecas, nas quais se tem que obedecer a regras rígidas de comportamento, código de conduta próprio ("silêncio" incluído) e em que os utilizadores não 
contribuem, nem alteram conteúdos, mas, sim, acedem ao que a Biblioteca tem disponível (assim como os conteúdos na Web 1.0), nas suas estantes ou em linha. Já na versão "2.0", a Web passou a ser um espaço para "ser e estar" (PELTIER-DAVIS, 2009, p.19), acontecendo o mesmo com os espaços físicos da Biblioteca, de acordo com o preconizado por Bolonha, espaços mais dinâmicos, mais abertos, incluindo espaços próprios para o estudo em grupo, onde os utilizadores podem estar mais à vontade e, inclusive, falar sem ser em "surdina". Em nível de conteúdos e serviços, também a Biblioteca 2.0 deve-se orientar pela criação centrada no utilizador e nas comunidades a que serve. Isto é, a Biblioteca que por séculos foi fonte de enriquecimento científico-cultural da comunidade, agora é ela própria a enriquecer com os seus utilizadores, pela sua comunidade. Receber e incentivar a participação da comunidade para a melhor servir, como uma parceria de confiança entre pares, em uma sociedade que visa promover o bem-estar e a riqueza comum.

Urge, então, verificar e estabelecer o que se entende por "Biblioteca 2.0". Analisando, na literatura, os conceitos fundamentais avançados por vários autores para o termo "Library 2.0" (termo original em inglês usado doravante, neste texto ,com o mesmo significado de "Biblioteca 2.0"), destacam-se os autores Casey \& Savastinuk (2006) e Maness (2006). Foi Casey \& Savastinuk quem primeiro cunhou o termo "Library 2.0" enunciando-o como o uso de serviços de software social nas bibliotecas, argumentando que as bibliotecas, usando estas tecnologias, poderiam oferecer um novo modelo de serviço que encorajasse "uma mudança constante e significativa, convidando à participação dos utilizadores na criação de serviços físicos e virtuais que desejassem" (CASEY; SAVASTINUK, 2006 apud RUTHERFORD, 2008, p. 412). Esta definição gerou uma série de discussões sobre o âmbito e conceitos associados a esse termo, sendo que terá sido Maness (2006) um dos autores que melhor elaborou uma perspectiva crítica sobre o mesmo e que sintetizou no artigo Library 2.0 Theory: Web 2.0 and Its Implications for Libraries, definindo "Library 2.0" como "a aplicação da interação, colaboração, e tecnologias multimídia baseadas na Web a serviços e coleções de bibliotecas" (MANESS, 2006, on-line), sugerindo que esta definição seja adoptada pela comunidade biblioteconômica. Isto é, Maness limita a definição a serviços $W e b$, redefinindo a de Casey \& Savastinuk, que a tinha enunciado para todos os serviços da biblioteca.

Maness avança com quatro elementos essenciais para que uma Biblioteca seja "2.0":

a) é centrada no utilizador: os utilizadores participam na criação de conteúdos e serviços que eles veem na presença da biblioteca na Web, OPAC, etc. O consumo e a criação do conteúdo é dinâmica e, por isso, as funções do bibliotecário e do utilizador nem sempre são claras;

b) oferece uma experiência multimídia (apenas como uma recomendação); 
c)é socialmente rica: a presença da biblioteca na Web inclui a presença dos utilizadores, formas síncronas (e.g. mensagens instantâneas) e assíncronas (e.g. blogues) para os utilizadores comunicarem entre si e com os bibliotecários; e

d) é inovadora a nível comunitário: bibliotecas como serviço comunitário; as comunidades mudam e as Bibliotecas não devem apenas mudar com elas, elas devem permitir que os utilizadores mudem a Biblioteca. A Biblioteca deve continuamente achar novas formas de permitir que as comunidades, e não apenas indivíduos isolados, pesquisem, encontrem e usem a informação.

Maness (2006) avança, também, com o conceito de "Library 2.0" como um mashup: híbrido de blogues, wikis, streaming media, agregadores de conteúdo, mensagens instantâneas e redes sociais; este permite ao utilizador editar os dados e os metadados do OPAC, salvar tags, conversas por mensagens instantâneas com bibliotecários, entradas wiki com outros utilizadores (e catalogar tudo isso para o uso e benefício dos restantes), podendo o utilizador escolher que elementos apareceram no seu perfil público; os utilizadores podem ver que itens similares outros utilizadores consultaram e um enorme catálogo, feito pelos utilizadores, é criado e mesclado com o catálogo tradicional (isto é, um mashup de serviços tradicionais de biblioteca e serviços inovadores Web 2.0). Maness (2006) defende ainda que Biblioteca 2.0 revoluciona a profissão. Em vez de criar sistemas e serviços para os utilizadores, os bibliotecários irão possibilitar que os utilizadores criem estes sistemas e serviços para seu próprio uso. "A Biblioteca 2.0 não é sobre pesquisar, mas sim sobre encontrar; não é sobre acesso, mas sim sobre partilha. A Biblioteca 2.0 reconhece que os seus utilizadores pesquisam informação não enquanto indivíduos, mas enquanto membros de uma comunidade" (MANESS, 2006, on-line)

Como Rutherford (2008) indica, compilando vários autores, o uso de software social no âmbito de operação das bibliotecas pode ajudar a manter os seus serviços relevantes para as necessidades dos seus utilizadores (RUTHERFORD, 2008, p. 413). Outro aspecto que esta autora indica é que, apesar dos artigos sobre matérias conceptuais ligadas a "Library 2.0" serem abundantes, existe uma lacuna evidente na exploração do impacto real do software social pelos bibliotecários / bibliotecas que o estão a usar, sendo que, no artigo "Building participative library services: The impact of social software use in public libraries" (RUTHERFORD, 2008), a autora expõe o estudo efetuado com vista à analisar o mesmo, concluindo que os entrevistados acreditam seriamente que a implementação desses serviços faz parte da sua missão, mas que todas as suas potencialidades ainda não estão a ser exploradas nas bibliotecas públicas alvo desse estudo (tidas como modelos, em nível 
mundial, na implementação de software social, em um total de doze, dos Estados Unidos e da Nova Zelândia).

\section{Novo paradigma de Descoberta de Informação Científica: Pesquisa 4.0}

Na linha do pensamento de James Surowiecki, colunista do The New Yorker e autor de The Wisdom of Crowds - Why The Many Are Smarter Than The Few And How Collective Wisdom Shapes Business, Economies, Societies And Nations (SUROWIECKI, 2004), para chegar a decisões de superiores - muitas vezes, melhor do que aquelas que tomadas por indivíduos, mesmo sendo eles 'especialistas' nesse campo, são necessárias formas sistemáticas de organizar e agregar a inteligência disponível. Embora a sua perspectiva seja a partir de uma visão corporativa (ele era um colaborador na edição da revista de referência na área da economia e gestão de empresas, Fortune), as suas ideias sobre como aproveitar a sabedoria coletiva da organização como a vantagem competitiva, pode ser transposta para as comunidades de indivíduos ou mesmo para o cenário de utilização de um usuário individual de um sistema de pesquisa e descoberta de informação, se mecanismos de agregação social e componentes participativos forem implementados. $\mathrm{Na}$ verdade, os princípios e propósitos são em tudo semelhantes, excetuando-se, talvez, a intensidade do fator competitivo, que tende a ser mais intenso no mundo empresarial.

Como nas redes sociais não mediadas por computador (comunidades físicas "tradicionais"), o indivíduo usa seus contatos para filtrar a informação que deve analisar e reter ou simplesmente para a validar, no contexto da pesquisa e descoberta de informação científica, usando os contatos que ele/ela tem neste ambiente de comunicação mediada por computador, esta mesma finalidade pode ser atingida, adaptando os processos e fluxos que ocorrem em redes humanas (na linha de pensamento de Dídac Margaix-Arnal para um OPAC social (MARGAIX-ARNAL, 2009, p. 24)). Na verdade, tendo canais específicos, talvez isso possa ser alcançado em um grau mais elevados, como a comunicação é muito direcionada no seu contexto e um conjunto de ferramentas para organizar o seu espaço de trabalho ou aprendizagem pessoal (PLE: Personal Learning Environment), ou mesmo com a ajuda dos grupos a que o/a mesmo/a pertence, permitem uma maior eficiência na gestão de uma miríade, em plena expansão, de fontes e recursos (embora vistos como mecanismos pessoais, estes podem servir, para o que Surowiecki (2004) enuncia como formas sistemáticas de organizar e agregar inteligência coletiva; veja-se, como exemplo, o uso de serviços como del.icio.us ${ }^{1}$ ou diigo ${ }^{2}$ ). Também o papel dos seus contatos como fontes de recomendação de recursos pode ser transposto para este novo

\footnotetext{
${ }^{1}$ Disponível em: <http://www.delicious.com>. Acesso em: 08 set. 2012.

2 Disponível em: <http://www.diigo.com>. Acesso em: 08 set. 2012.
} 
cenário, a fim de tirar o máximo partido do seu potencial (ALAG, 2009 apud MARGAIX-ARNAL, 2009, p. 25).

Neste cenário, folksonomias, crowdsourcing, inteligência coletiva, sabedoria das massas desempenham um papel fundamental em um novo paradigma de Descoberta de Informação Científica, que designamos de Pesquisa 4.0. Com esta designação, desejamos enfatizar as 4 dimensões: pesquisa, descoberta, acesso, recomendação e partilha de recursos, resultante de uma dinâmica social entre os quatro elementos-chave: utilizador, recursos, mapeamento semântico de metadados (vários milhões de registros indexados localmente) e comunidades/redes sociais do utilizador (seus pares, utilizadores com interesses comuns). Em plena interação, potenciada por um sistema de suporte adequado, estes quatro elementos geram uma rede social dinâmica, autossustentável, autopoética e com garantia de preservação futura. Uma rede social não só de atores humanos, mas dos recursos em si, assumindo, assim, também, estes, 0 papel de atores no sistema. Em um cenário de "Pesquisa 4.0", os recursos assemelham-se a outros objetos na "Internet das Coisas" e a principal característica da "Web 4.0", uma maior integração em tempo real entre indivíduos e objetos, com que interagem através de mundos virtuais ou serviços. O resultado final pretendido: uma rede social com um capital cultural e social superior, com benefícios mútuos não só para os atores humanos, mas, também, para os próprios recursos.

Os atores humanos podem "vir e ir", mas o valor que eles adicionam ao interagirem com os recursos (adicionando valor aos mesmos de forma ativa ou apenas pelo seu uso, já estão a adicionar valor aos mesmos, de forma passiva, dado que esse registo pode ser usado para os recomendar a utilizadores com interesses idênticos), esse permanecerá.

\section{0 derradeiro elemento que potencia a Descoberta em Contexto: a componente Social}

Neste novo paradigma de "Pesquisa 4.0", a componente de Comunidade, a dinâmica de interação social dos utilizadores assume um papel de extrema importância não só pelas interligações que se estabelecem entre os atores humanos, destes com os atores "informacionais" (recursos) e entre estes mesmos, via ligações semânticas ou potenciadas pela informação adicional adicionada pelos atores humanos. Acima de tudo, para além dos seus gostos ou preferências, 0 elemento social dos utilizadores, a informação relativa a que Comunidades pertencem, é o verdadeiro elemento determinante para facultar a derradeira experiência em termos de descoberta de Informação Científica, em especial perante o cenário cada vez mais real de haver Serviços de Descoberta que não só englobam recursos locais como uma miríade de recursos externos (milhões de registos), abundante em fontes, mas, também, em conceitos e cobertura de temáticas. 
Perante esta imensidão e abundância de recursos, que mesmo uma "equação de pesquisa" bem elaborada resulta em uma extensa lista de resultados, como se pode garantir que os resultados em primeiro lugar são realmente os mais relevantes?

A relevância atribuída a um determinado recurso no contexto de uma determinada pesquisa, por mais ou menos complexa que seja a sua equação ou fórmula de cálculo subjacente, sempre foi encarada como uma mera média ponderada resultante da soma da frequência dos termos pesquisados, atribuindo valores diferentes aos campos onde os mesmos aparecem, no caso da pesquisa por "palavra-solta", pela sua proximidade no registo (no mesmo ou em diferentes campos do mesmo [apenas na pesquisa por "palavra-solta"]). Nesta equação e recentemente, em especial em meios académicos, começou a adicionar-se o valor da "data de publicação", maior quanto mais recente for a mesma (em especial no campo das ciências exatas, mas importante em qualquer área, dada a vertiginosa evolução do conhecimento, em que uma determinada teoria ou equação considerada "referência base" se torna obsoleta em menos de uma década).

Contudo, por muito bem que esteja "afinada" essa equação, seja rica em micro-critérios de avaliação, atingir o que podemos aqui também chamar de "efeito Google", de o(s) recurso(s) pretendido(s) estar(em) na primeira página de resultados (idealmente nos primeiros 10), muito dificilmente se conseguirá dada a referida enorme oferta base de recursos. E aqui, à semelhança da notória valorização dos termos de pesquisa sugeridos apresentados pelo Google quando se começa a escrever o pretendido, uma valorização facilmente identificada com o chamado "trending" (isto é, temas mais em voga no momento, sejam relativos a acontecimentos da atualidade, sejam relativos a novos filmes ou outros recursos de entretenimento), a componente social, global ou de uma Comunidade específica pode fazer a excelsa diferença e dar mais relevância a recursos que são realmente relevantes nesse determinado contexto. Pesquisas, temas ou recursos mais populares, nada mais são que o espelho de puro, supramencionado, "crownsourcing". Se ao mesmo introduzirmos uma componente de valorização local ou da comunidade, os Serviços de Descoberta podem oferecer a verdadeira experiência "Google" e algo mais: os recursos mais relevantes, não só nesse momento como o Google aparenta dar mais relevância, mas acima de tudo para o utilizador em questão.

A envolvente social do utilizador, facilmente determinável num meio académico (pois frequenta um determinado Curso, está inscrito em determinadas Unidades Curriculares, é investigador numa determinada área, etc.), complementada com, ou tendo pelo menos como base, a fornecida pelo mesmo no seu perfil, pelos seus "gostos", partilhas, comentários, etc., é a derradeira dimensão extra que até agora faltava aos sistemas de pesquisa, lineares, unidimensionais por natureza, dada a sua concepção mais tecnicista. O usuário passa de facto a ser considerado uma pessoa pelo sistema, com um percurso histórico de pesquisa e com 
uma rede social na qual essa pesquisa se insere, ou seja, a Pesquisa 4.0 é contextual, não apenas do ponto de vista semântico, mas também social.

Esta dimensão social habilita os Serviços de Descoberta com a possibilidade de implementarem algoritmos "inteligentes", adaptáveis e evolutivos. Ao acumularem uma cada vez mais rica coleção de dados de inteligência obtidos de cada Comunidade de utilizadores que servem, como massa crítica que é, estes permitem-lhe de certa forma "emular" a componente de avaliação e seleção. Um Serviço de Descoberta, por mais dados que tenha (e poder de computação para os tratar, usando algoritmos inteligentes), jamais poderá substituir a componente humana fulcral da Literacia Informacional que é a relativa ao pensamento crítico. Sem prejuízo para essa constatação, podemos de certa forma considerar essa componente facilitada pelo Serviço de Descoberta, a de avaliação e seleção, como uma versão elementar do mencionado "pensamento crítico".

Figura 1 - O fluxo base (continuo) da Literacia Informacional

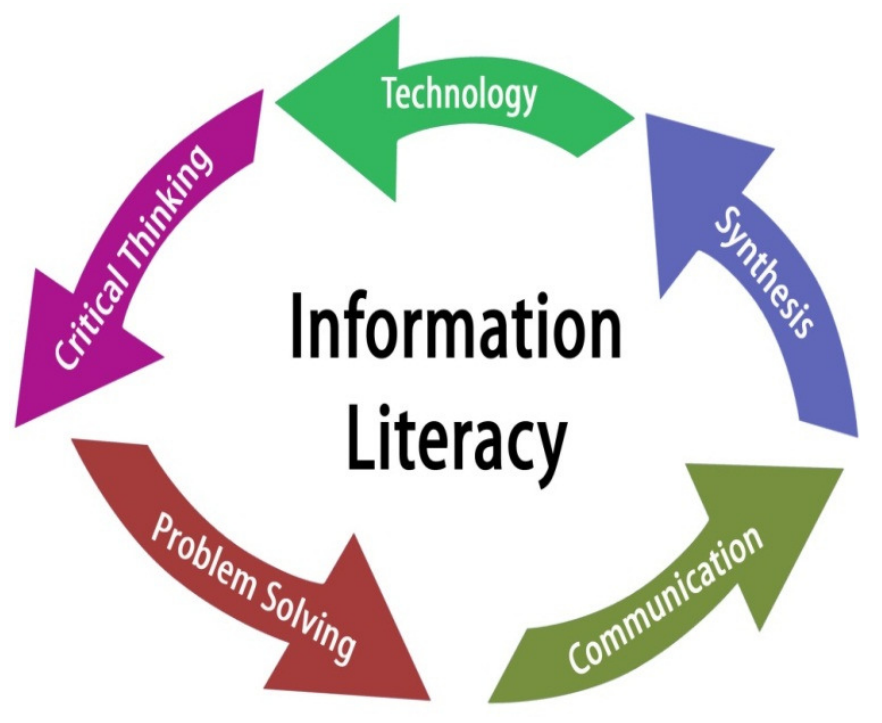

Fonte: PILOIU (2013).

O conceito aqui avançado de "Pesquisa 4.0", implementado na componente operacional de um Serviço de Descoberta, permitirá "ajudar" os seus utilizadores nas cinco etapas afetas à literacia informacional (ilustradas na Figura 1), potenciado a sua autonomia no processo de pesquisa, análise crítica e seleção da informação, que após ser transformada em conhecimento, deve possibilitar e potenciar a sua partilha com a comunidade, que inclusive pode estar presente, ajudar em todas as etapas.

\section{Considerações finais}

No modelo proposto para "Pesquisa 4.0", caracterizado por se basear em novas dinâmicas de pesquisa e descoberta de informação científica e cooperação entre investigadores, potenciadas por sistemas de agregação de informação e da atividade dos seus atores, os recursos se 
assemelham a objetos na "Internet das Coisas" e a principal característica da "Web 4.0", uma maior integração em tempo real entre indivíduos e objetos. Se incluirmos num sistema de "Pesquisa 4.0" componentes de agregação de conteúdo, preferencialmente usando algoritmos inteligentes de recuperação de informação relacionada e relacional, pode-se dotar os utilizadores de um ponto de pesquisa e descoberta rico, quer por ser um agregador de várias fontes, quer pela sua componente participativa/colaborativa, com possíveis mais-valias na criação e identificação de comunidades de utilizadores com interesses comuns.

\section{Referências}

ALAG, S. Collective intelligence in action. Greenwich, CT: Manning, 2009.

CASEY, M.; SAVASTINUK, L. Library 2.0: service for the next-generation library. Library Journal, v. 131, n. 14, p. 3, 2006.

MANESS, J. M. Library 2.0 theory: web 2.0 and its implications for libraries. Webology, v. 3, n. 2, 2006. Disponível em: <http://www.webology.ir/2006/v3n2/a25.html\#7>. Acesso em: 17-122013.

MARGAIX-ARNAL, D. L'OPAC social i la participación dels usuaris als catālegs bibliogrāfics - EL OPAC Social y la participación de los usuarios a los catálogos bibliográficos. Item: revista de biblioteconomia i documentació, núm. 50, p. 17-30, 2009. Disponível em: < http://eprints.rclis.org/14735/1/ITEM ELIS.pdf>. Acesso em: 17-12-2013.

PELTIER-DAVIS, C. Web 2.0, library 2.0, library user 2.0, librarian 2.0: innovative services for sustainable libraries. Computers in Libraries, v. 29, n. 10, p.16-21, 2009.

PILOIU, R. Home - information literacy - libguides at Otterbein University. 2013. Disponível em:

http://otterbein.libguides.com/content.php?pid=127135>. Acesso em: 17-12-2013.

RUTHERFORD, L. L. Building participative library services: the impact of social software use in public libraries. Library Hi Tech, v. 26, n. 3, p. 411423, 2008. .

SUROWIECKI, J. The wisdom of crowds: why the many are smarter than the few and how collective wisdom shapes business, economies, societies, and nations. New York: Anchor Books, 2004. 